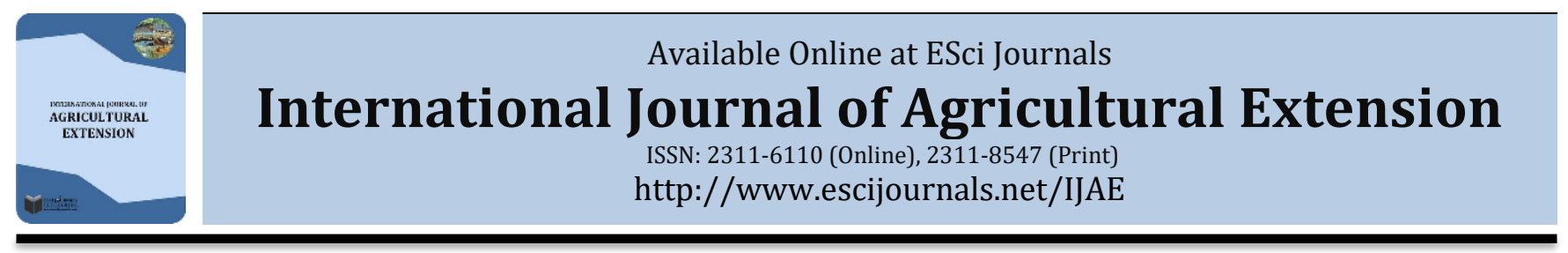

\title{
ASSESSING EFFICIENCY OF ACTION AID SIERRA LEONE (AASL) EXTENSION SERVICES IN SIERRA LEONE
}

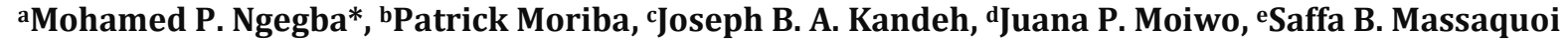 \\ ${ }^{a}$ Department of Extension and Rural Sociology, School of Agriculture, Njala University, Sierra Leone. \\ ${ }^{b}$ Regional Head Quarter Office, Action Aid, Bo Town, Sierra Leone. \\ c Department of Agricultural Education and Home Economics, School of Education, Njala University, Sierra Leone. \\ ${ }^{d}$ Department of Agricultural Engineering, School of Technology, Njala University, Sierra Leone. \\ ${ }^{e}$ Research and Innovation Unit, Agriculture and Forestry Department, Eastern Polytechnic Kenema, Sierra Leone.
}

\section{A B S T R A C T}

This paper investigated the participation of the beneficiaries of agricultural extension services run by Action Aid Sierra Leone (AASL) - A British-based non-profit and non-governmental organization. The study was conducted in Wonde Chiefdom (which is in Bo District, Sierra Leone) where all the 10 rural communities with AASL extension services were targeted. Out of the total 8291 of beneficiary household in the 10 communities, 250 were randomly covered in the survey, involving both quantitative and qualitative data. The study showed that AASL uses an integrated holistic approach to community development. Most of AASL extension services rendered were on child sponsorship (90.0\%), women's rights advocacy (78.8\%), gender awareness creation (69.6\%) and adult literacy (67.6\%) programs. Beneficiary participation was high (96.0\%) in the provided services and facilities. It was concluded that AASL should involve multi-stakeholders and encourage similar partnerships in the introduction of agricultural extension services and the associated facilities in the investigated Chiefdom.

Keywords: Action Aid, Sierra Leone, Stakeholder partnership, Extension service.

\section{INTRODUCTION}

Like the United Nations (UN), the primary objective of (local or international) Non-Governmental Organizations (NGOs) is to lift the world out of poverty (Chiang, 1981; Weiss and Gorenker, 1996), which can be achieved via multiple means; including education, rights protection, access to resources, medical/health care all of which contribute to raising the standard of living of the world's poor.

Action Aid is an international non-profit and NGO that focuses primarily on the protection of human rights and alleviation of poverty in all communities across the world. It uses rights-based approach to development and works on the premise that every person is entitled to the same basic human rights and that securing these rights is the key to poverty reduction. Action Aid helps to organize and mobilize rural people and develops them

* Corresponding Author:

Email: mngegba@njala.edu.sl

(C) 2018 ESci Journals Publishing. All rights reserved. power to negotiate (Gale et al., 2013). Action Aid Sierra Leone (AASL) was first established in 1988 as a national association dedicated to the rights of refugees. Currently, AASL is present in 6 (out of 12) districts in Sierra Leone and then in the Western Area (Figure 1). AASL started work in Bo District in 2005 and currently covers 3 chiefdoms (Kakua, Baoma and Wonde) in the district, which together comprises 283 villages with an estimated population of 257 097, of which 51.7\% (132 919) are women. Wonde Chiefdom has the least number of formal/community schools (8) in Bo District, with a total enrolment of 2530 and only $37.7 \%$ (954) of whom are girls. In fact, there is no secondary school in the chiefdom and school dropout rate is one of the highest in the district (MAFFS, 2015).

AASL helps farmers in Wonde Chiefdom (one of the 3 socalled Development Areas, DA) with the production of food crops and the management of income generation activities. It has been providing agricultural extension services and community facilities in the region for some 
11 years now. This is long enough period to have a development footprint such as improved standard of living and food security in beneficiary households or communities. However, observations suggest that most of the inhabitants of the chiefdom still struggle for balanced daily meal. The farmers have never shifted from small farm sizes and saved farm products are not enough for the year. There is no access to regular markets in the neighbourhood and farmers therefore travel several kilometres to the nearest weekly markets to sell farm produce or buy basic household needs. Even at the markets, most farm commodities are credited to wholesalers who delay payments by several weeks.

Though, Action Aid services and facilities are intended to improve the socio-economic status of farmers and other inhabitants of Wonde Chiefdom, this enhancement is yet to be achieved. Most homes do not have improved toilet facilities and the farmers still use the same crude farming tools. In fact, some communities still lack basic education facilities, implying that children have to walk kilometers away to attend the nearest school. Some of the inhabitants are not even aware of the services and facilities provided by Action Aid in the chiefdom (MAFFS, 2015). Thus, it is legitimate to wonder about: a) what services and facilities Action Aid actually provides in Wonde Chiefdom; b) what level of efficacy are the services and facilities provided; and c) what is the level of involvement of the beneficiaries in the services and facilities introduced in the chiefdom? These questions are essential because people's involvement in their own development programs is a more viable and sustainable approach to project implementation (Christoplos, 2010). Popular participation in development programs creates a feeling of belongingness and ownership, encouraging beneficiaries to contribute their own resources for successful development operations. It gives a grassroots face to development projects, making such projects appear more bottom-up and sustainable in nature than otherwise.

Most field workers in AASL extension services, especially the village-level extension agents, are contracted from the Ministry of Agriculture, Forestry and Food Security (MAFFS). In most cases, these field workers are nonresidents of the communities they serve, and they only visit the communities once in a fortnight (MAFFS, 2015). Furthermore, any contacts with the field-level extension agents are impossible outside the time of community visits. However, to build a true culture of sustainable development, rural people should be in constant interaction with extension agents. These contacts can serve a forum for new learning experiences that supplement formal education towards strategic capacity building. Farming is a time-bound activity where every input must be timely for maximum output. For successful community development programs, extension agents should be available at the times when technical advice on farm operations is needed. Not only do farmers in Wonde Chiefdom lack ready access to extension agents, but there is also no record on extension services, facilities and beneficiary participation in Action Aid activities in the area.

Thus, this study investigated the cause of the discrepancy between AASL agricultural extension services/facilities (development input) and the standard of living of beneficiary communities (development output) in Wonde Chiefdom. To achieve this main objective, the study emphasized to;

- Identify the resources (services and facilities) provided by AASL and the beneficiary communities in Wonde Chiefdom

- Determine perceived degree of usefulness, utilization and efficacy of AASL resources in beneficiary communities in Wonde Chiefdom

- Assess the level of participation of beneficiary communities in the development and implementation of AASL development packages in Wonde Chiefdom.

While the founding objectives of most NGOs and/or even governments are people-oriented, the implementation strategies of such objectives could be fundamentally flawed. The findings of the study could guide the roles and point of entry of Action Aid, other NGOs and the local/national governments in community development. The data collected in the study could also be used to recalibrate operational strategies so as to minimize weaknesses and strengthen successes of community development efforts. To sum it up, the findings of the study will have beneficial implications for the billions of the world's poor and contribute significantly to the millennium development goal of the United Nations.

\section{METHODOLOGY}

Study Area: This study covered all the operational areas of AASL in Wonde Chiefdom. Wonde, one of the 15 chiefdoms in Bo District, lies some $32 \mathrm{~km}$ southeast of Bo Town - the second largest city in Sierra Leone (Fig. 1). The chiefdom is comprised of 5 sections (Kawa et al., 2017) and has a population of about 15265 (SSL, 2014). Although Krio is 
the most spoken lingua-franca, the dominant (over 80\%) ethnicity is Mende, sharing the region in harmony with the Sherbro, Temne, Susu, Fula and Mandingo. Also, the predominantly Muslim population (60\%) live peacefully together with its Christian counterpart.

The vegetation in the study area is characterised by secondary tropical rainforest, interspersed with low shrub of various tree species that is today the source of firewood and timber. The soil is dark brown to black in color, granular in structure, very porous and slightly acidic. The patches of largely plant-based organic matter make the land generally fertile for crop cultivation.

The annual precipitation is over $4000 \mathrm{~mm}$ and it occurs for up to six months (April to October) in the year. Temperatures are high throughout the year, with an annual average of $31^{\circ} \mathrm{C}$. The topography is generally undulating, with small stretches of low plains and Inland Valley Swamps (IVS). Although each individual IVS is small in size (generally less than 100 acres), it is highly suitable for paddy rice cultivation throughout the year. Despite the rich soils, numerous IVS, high precipitation and conducive other weather conditions, agricultural productivity in the study area (like in most of Sierra Leone) is low; making food security vulnerable.

As road network in the study area is very poor, access to the chiefdom is very difficult (if not impossible), especially at the peak of the rains during the wet season. At the moment, there are two main Junior Secondary Schools (JSS) in Wonde Chiefdom - one in Mboyama and the other in Bathurst, the chiefdom headquarter town. Only a few educational programs are operational in the chiefdom, with limited teaching and learning materials. Also because of lack of primary health care facilities, only Traditional Birth Attendants (TBAs) serve in the village communities in the chiefdom. Any two nearest health centers in the chiefdom can be some $16 \mathrm{~km}$ apart.

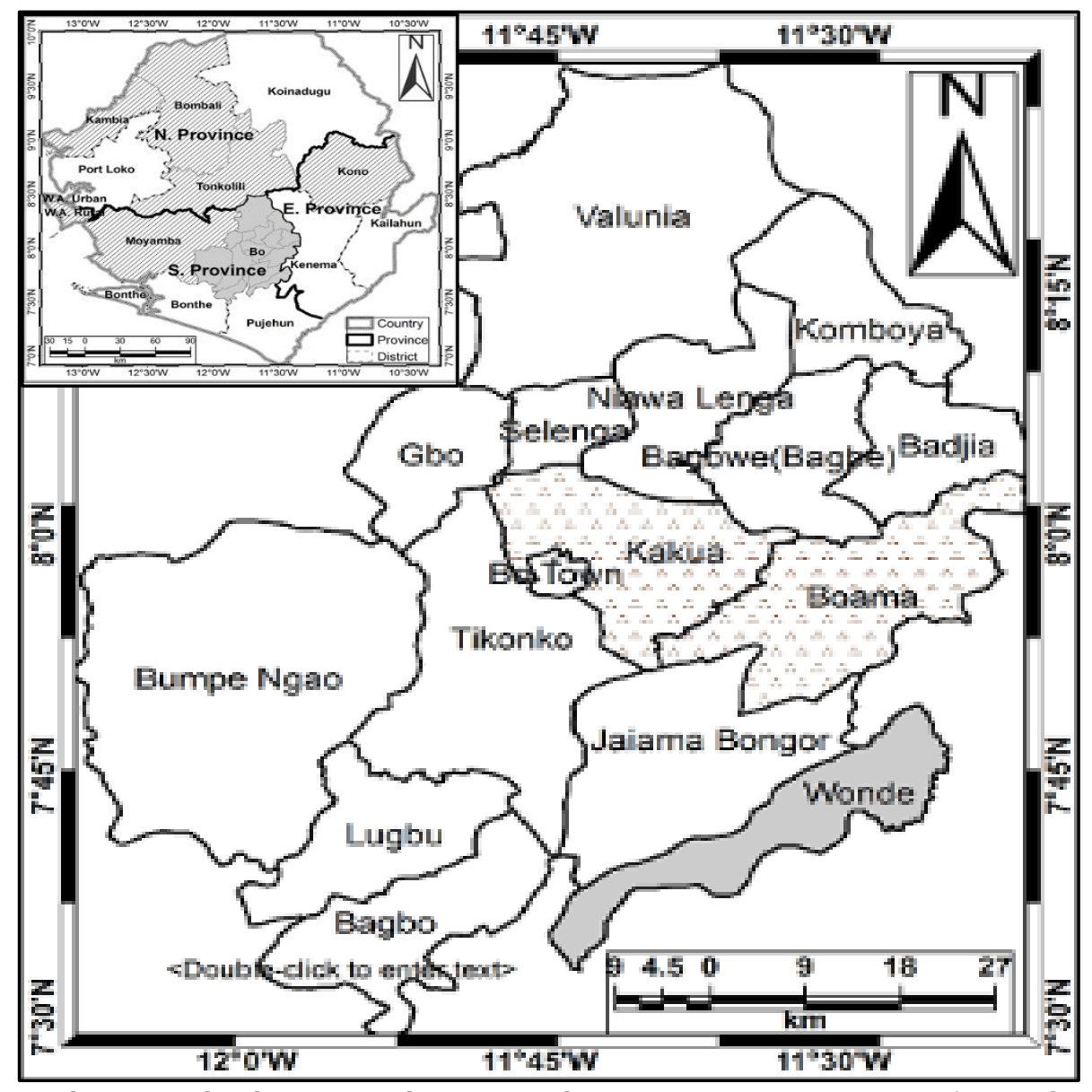

Figure 1. A map depicting the districts with Action Aid operations in Sierra Leone (inset plate at top left corner) and an expanded map of all the 15 chiefdoms in Bo District plus Bo Town (main plate) showing specifically the three chiefdoms with Action Aid programs, with the shaded grey one as the Wonde Chiefdom study area. 
Sampling Method: Wonde Chiefdom was purposively selected for this research because it is one of the poorest and among the least developed chiefdoms in Bo District. Also because of limited resources for the study, only 10 village communities (Table 1) were randomly selected for data collection.

Going by AASL nomenclature, regions identified for development intervention services are called Development Areas (DA). In a DA, a household is a group of people whose meal come from the same pot implying that there can be more than one household under the same roof. Based on this nomenclature, the number of households in each of the selected 10 villages and the number of households included in the study per village are listed in Table 1.

About $3 \%$ of the households in each of the 10 randomlyselected village communities were again randomly selected for participation in the study. Also, irrespective of the size of each randomly-selected household in a community, only one person (the household head) was interviewed. Based on the above selection criteria (purposive due the socio-economic conditions, small due to financial constraints and random to limit bias), a total of 250 (out of 8291) households were included in the study for data-collection (Table 1). It was assumed that household heads have the most complete information about developmental changes in the households and communities with significant impact on the livelihood of household members, including changes in demographic, socio-economic, agricultural, educational and environmental conditions. All the services promoted by AASL (Table 1) were covered in the study.

Questionnaire Development: Like in most socioeconomic surveys, questionnaire was the primary data collection instrument in the study. The questionnaire consisted of closed-ended and Likert-scale questions, but also had provision for guided discussions and interpersonal interactions guided by household heads. The questionnaire was divided into four sections, each dealing with a specific aspect of the characteristics of the respondent or the community.

The questionnaire was tested on 32 representative respondents in the neighboring Boama Chiefdom, validated and upgraded (based on identified issues) before final use in the survey. The validation and upgrading phases of the questionnaire included expert inputs from extension, education, health, agriculture and development officials. This was followed by reliability test, involving 16 fresh respondents. It included: 1) administration of the questionnaire to the same respondents on two occasions at an interval of two weeks and the scores analyzed for Pearson ProductMoment Correlation - r). Using the split-half method as a measure of internal consistency by dividing the administered questionnaire into two based on odd-even numbers and the scores again analyzed for $r$ correlation. In both cases, $r$ value for the reliability test was above 0.78 . This suggested that the instrument of the survey (the questionnaire) was reliable and therefore fit for application in the study.

Data collection: The fully developed and tested questionnaire was used to collect data in the 20-day survey, started on the 20th of June and ended on the 10th of July 2017. Both primary and secondary data were collected in the survey. For the primary data, 4 well-trained enumerators (with good communication skills in English, Krio and other local dialects) were recruited for the data collection. Then the secondary data were collected through desk research from published literature, research papers, journals, books, project reports, official documents, guided discussions.

The 4 recruited enumerators and the lead researcher were involved in the collection of the primary data using the questionnaire. A total of 250 questionnaires were administered in 10 village communities across the Wonde Chiefdom in Bo District (Table 1). The questions were read out and translated to the farmers in the preferred dialect or lingua franca and the responses recorded accordingly on the questionnaires. Personal observations were also recorded in special field notebooks as part of the secondary data. The completed questionnaires (plus field notebooks) were taken back to the office and processed by the lead researcher for collected data. The data were next statistically analyzed and presented in the next sections.

Service efficacy: Here, efficacy is the measure of the existence of a real need for a service provided by AASL in a community. The need for a provided service is assessed on a 5-point Likert-scale based on the level of accessibility, affordability, suitability, usability and sustainability of the service. From the above definition, the level of efficacy of AASL-provided services in rural communities in the study area was determined. Participation and implementation, on the other hand, was each measured on 2-point yes-or-no scale. Also note that the services provided by AASL are abbreviations in 
some of the tables and figures as: $\mathrm{CS}=$ child sponsorship, $\mathrm{TC}=$ toilet construction, $\mathrm{FA}=$ farmers' association, $\mathrm{AL}=$ adult literacy, $\mathrm{HE}=$ health education, $\mathrm{FT}=$ farm training, $\mathrm{WW}=$ water well construction, $\mathrm{FP}=$ food preservation,
$\mathrm{FF}=$ food for work, $\mathrm{GA}=$ gender awareness, $\mathrm{IP}=$ improved planting materials, $\mathrm{WR}=$ women's rights, $\mathrm{MC}=$ micro-credit, $\mathrm{FD}=$ field day, $\mathrm{SC}=$ school construction, $\mathrm{FP}$ $=$ food processing, $\mathrm{CM}=$ constructing markets.

Table 1. A list of the 10 villages targeted for data collection in Wonde Chiefdom. Note that the first part lists the total number of beneficiary households per community and the households that participated in the study. Then the second part lists the services provided in the communities.

\begin{tabular}{|c|c|c|c|c|}
\hline Village & Total household & Sampled household & Provided service & Code \\
\hline \multirow{2}{*}{ Bathurst } & \multirow{2}{*}{1099} & \multirow{2}{*}{33} & Child sponsorship & $\mathrm{CS}$ \\
\hline & & & School construction & $\mathrm{TC}$ \\
\hline \multirow{2}{*}{ Fanima } & \multirow{2}{*}{966} & \multirow{2}{*}{29} & Farming training & FA \\
\hline & & & Toilet construction & $\mathrm{AL}$ \\
\hline \multirow{2}{*}{ Fayama } & \multirow{2}{*}{799} & \multirow{2}{*}{24} & Health education services & $\mathrm{HE}$ \\
\hline & & & Women's rights advocacy & FT \\
\hline \multirow{2}{*}{ Gawula } & \multirow{2}{*}{866} & \multirow{2}{*}{26} & Water-well construction & WW \\
\hline & & & Food preservation services & $\mathrm{FP}$ \\
\hline \multirow{2}{*}{ Kambawama } & \multirow{2}{*}{732} & \multirow{2}{*}{22} & Improved planting material & $\mathrm{FF}$ \\
\hline & & & Gender awareness services & GA \\
\hline \multirow{2}{*}{ Kornia } & \multirow{2}{*}{766} & \multirow{2}{*}{23} & Adult literacy services & IP \\
\hline & & & Farmer association building & WR \\
\hline \multirow{2}{*}{ Nyiagoihun } & \multirow{2}{*}{799} & \multirow{2}{*}{24} & Food processing services & $\mathrm{MC}$ \\
\hline & & & Field-day services & FD \\
\hline \multirow{2}{*}{ Njala } & \multirow{2}{*}{666} & \multirow{2}{*}{21} & Market services & $\mathrm{SC}$ \\
\hline & & & Food-for-work services & FP \\
\hline \multirow[b]{2}{*}{ Pelewahun } & \multirow[b]{2}{*}{932} & \multirow[b]{2}{*}{28} & Micro-credit services & $\mathrm{CM}$ \\
\hline & & & & \\
\hline Yanihun & 666 & 20 & & \\
\hline Total & 8291 & 250 & & \\
\hline
\end{tabular}

Data Analysis: Data were analyzed using the SPSS (Statistical Package for Social Sciences). Since the research studied mainly the socio-economic characteristics of the respondents and respondent communities due to interventions by AASL development agency, the analysis was mainly descriptive. Also, a limited correlation analysis was done to establish the relationship between some variables. This included frequency and percentage statistics of the respondents and communities in the study area.

\section{RESULTS AND DISCUSSION}

Personal Attributes: The personal attributes of the respondents are summarized in Table 2 , suggesting that (58\%) the beneficiaries of AASL extension services were in the prime age; of which $25 \%$ were in age range $26-35$ years and another 33\% in the next age range 36-45 yr. Generally, this was the most active and productive age of the population and therefore the population fraction with the highest likelihood for success in most undertakings. The level of activity of this age group was demonstrated by its high participation in AASL programs in the investigated communities. Of the total respondents, $67 \%$ were male and $76 \%$ Muslims. In spite of the male-dominance, a good number $(33 \%)$ of the rural women were associated with community programs. However, most of the women in AASL programs were either single, divorced or widowed; making up $28 \%$ of the women participants.

Also, some $67 \%$ of the respondents $(32 \%$ with $<6$ and $35 \%$ with $6-10$ persons) had family size of 10 or less 
and another $76 \%$ were aware of AASL extension services in the community. Generally, the larger the family size, the higher the responsibility. This drove household heads to go out for more opportunities to meet this responsibility. This was a possible motivating factor for high participation of rural people in development activities in the communities.

The normal expectation is to build families through marriage, which explained the large percent (72\%) of married respondents on the one hand and the large family size on the other. Like most other countries in Africa and throughout the developing world, rural people are largely illiterate or at most have little formal education (Conteh et al., 2015). In the study area, only $6 \%$ of the respondents had tertiary education (not necessary university or even college education, but largely vocational education) and another $72 \%$ with informal education. The low educational level meant that the respondents were less critical and therefore participated in programs without much cost-benefit analysis (Kangoma et al., 2017). Lastly, most the rural people were farmers (89\%), with over 10 years of farming experience; the most common case for typical developing world.

Table 2. A table listing the distributions of the attributes of personal characteristics of Action Aid service beneficiaries in the Wonde Chiefdom study area of Bo District, Sierra Leone.

\begin{tabular}{lccccc}
\hline Variable & Attribute & Fraction (\%) & Variable & Attribute & Fraction (\%) \\
\hline \multirow{4}{*}{ Age } & $<26$ & 7.6 & Sex & Male & 67 \\
& $26-35$ & 24.8 & & Female & 33 \\
& $36-45$ & 33.2 & Religion & Christian & 24 \\
& $46-55$ & 16.6 & & Muslim & 76 \\
& $>55$ & 18.4 & \multirow{2}{*}{ ASA } & Aware & 76 \\
Household size & $<6$ & 32 & & Unaware & 24 \\
& $6-10$ & 35.2 & & Married & 72 \\
& $11-15$ & 9.6 & Marital status & Single & 4.8 \\
Farming experience & $>15$ & 3.2 & & Divorced & 7.2 \\
& $<6$ & 10.5 & & Widowed & 16 \\
& $6-10$ & 38.8 & & Primary & 15.2 \\
& $11-20$ & 40.6 & Educational status & Secondary & 7.6 \\
& $21-30$ & 6.9 & & Tertiary & 5.6 \\
\hline
\end{tabular}

Program Participation and Implementation: Figure 2 is a scatter-plot of beneficiary participation versus agency implementation of AASL-promoted services (Table 2) in the Wonde Chiefdom study in Bo District, Sierra Leone. From the plot, there is a high correlation ( $\mathrm{r}$ $=0.99$ ) between participation and implementation of AASL-promoted services in the study area. There is a high level of participation and implementation of most of the AASL-promoted services. While on average the beneficiary participation was $65.5 \%$, the agency implementation of the services was $58.4 \%$. While in part it was an indication of successful handling of AASLsponsored programs in the region, it also indicated the existence of a real need for the AASL-promoted services in the rural communities of Sierra Leone. It has been noted that there often exists a strong correlation between participation and implementation of projects (Comings, 1997; Markus \& Mao, 2004).

Implemented Services Efficacy: The levels of efficacies of AASL-sponsored services in the study area were ranked from high to low and plotted in Fig. 3. On the average, AASL-promoted services were very highly rated in the study area, with an average efficacy score of 61.9\% (horizontal grey line on plot in Fig. 3). In developing countries where poverty is vastly prevalent, tokens are apparently perceived to bring improvements in livelihoods and are therefore appreciated. Despite the rich abundance of mineral resources, Sierra Leone has always been listed among the least developed countries in the world in terms of human development index. With 
this, life in the rural areas was not expected to be smooth. Under this circumstance, an intervention perceived to bring positive changes in the livelihoods of the rural poor was readily embraced.

Efficacy was highest (86.1\%) for services related to child sponsorship, followed by school construction (84.2\%) and farmers' training (79.2\%) and it was least for microcredit (14.2\%) - Fig. 3. In fact, in the study area, all AASL-promoted services/facilities had a high efficacy, except 3 - market facilities (31.1\%), food for work (15.6\%) and micro-credit (14.2\%). In rural communities in poor developing countries like Sierra Leone, people feel most accomplished by having and raising children.

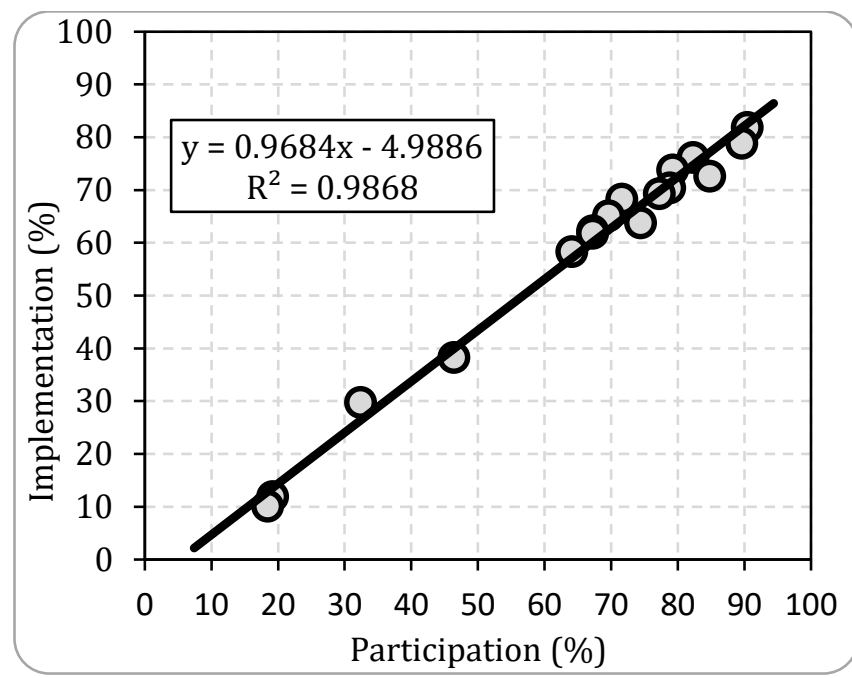

Figure 2. A scatter-plot of percent respondent participation versus agency implementation of AASLprovided services in the Wonde Chiefdom.

This is because children are viewed as the future of tomorrow, the future source of support for the sustenance of livelihoods. Children are seen just in the same way white-collar workers in urban milieus see pensions, gratuities, insurances or benefits as the sources of sustenance during old age. Thus, services related to children were often very highly supported. Building schools brought education to the doorstep of the people in poor rural communities. And with the ever-increasing and widespread impacts of modernization on the world, no one (not even the rural poor) wants to be left out. Thus, the construction of schools was strongly supported in the study area. While doing all of this, the rural poor were very conscious of the fact that they are farmers and therefore supported activities that helped them improve farm operation and brought in more farm income (Cumings, 1997; Conteh et al., 2015). Services that dealt with micro-credits had the least (but still rated successful at 58.0\% efficacy) interest because of the very bad experience that illiterate rural poor had with such service providers.

Bad governance is always a recipe for endemic corruption, which was pervasive in Africa and specifically in Sierra Leone. In Sierra Leone, the rural poor had recent experiences of massive exploitation through governmentdriven micro-credit programs. Instead of improving livelihoods, the program was cockishly manipulated to become the source of endless loss of money by the rural poor. This killed any interest that rural poor had in services related to micro-credit (Ghosh, 2010).

It was the same corrupt and unscrupulous officials who destroyed the well-intended food-for-work services for personal gains and wealth. Most farmers in rural Africa grow crops for subsistence and not for commercial market (Kangoma et al., 2017), thus the construction of markets was not so strongly welcome in the communities.

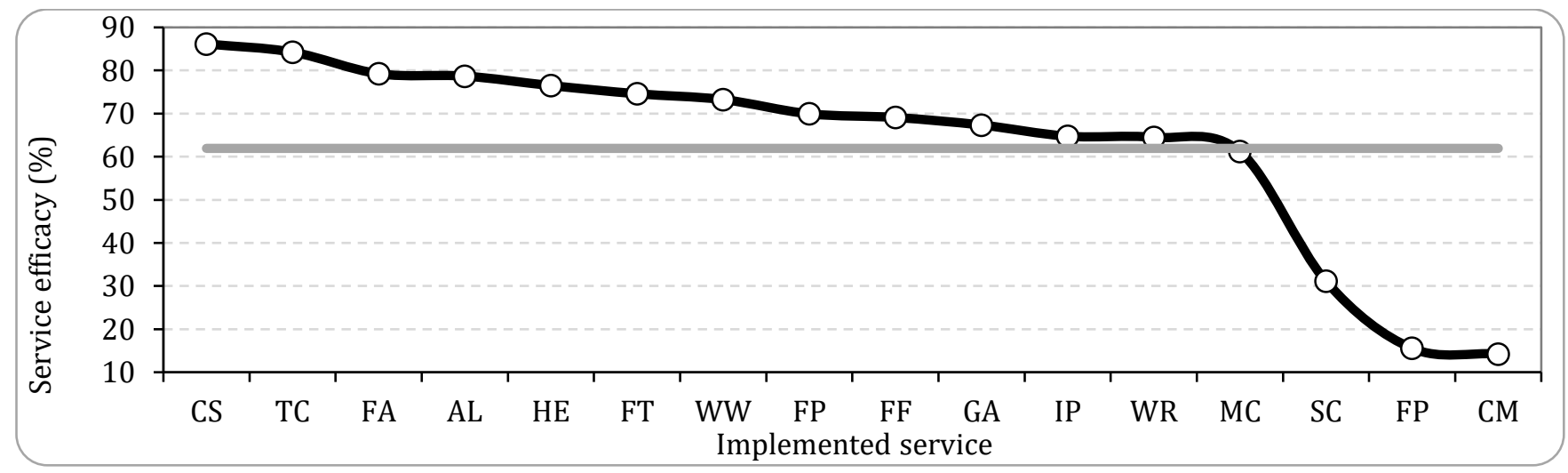

Figure 3. Dynamics of the efficiency of AASL-provided services in the Wonde Chiefdom study area in Bo District, Sierra Leone. The horizontal grey line indicates the percent average efficacy of the all the services. 
Correlativity of Efficacy: Using a scatter-plot, Figure 4 shows that efficacy was strongly correlated with both participation $\quad\left(\mathrm{R}^{2}=0.9968\right)$ and implementation $\left(\mathrm{R}^{2}=0.9966\right)$ of AASL-promoted services-both nearly equally influenced efficacy.

Studies show that success was participation-driven, and it was measurable via implementation (Markus \& Mao, 2004).

Discussion: AASL is a humanitarian, non-profit and nongovernmental organization that is a member of the consortium of the long-standing aid agencies in Sierra Leone. As an implementing agency of development aids with a strong global presence, AASL provides various community development services across Sierra Leone. This study investigated 17 of the key services provided in some AASL operational chiefdoms in Bo District. The services were assessed in terms of personal

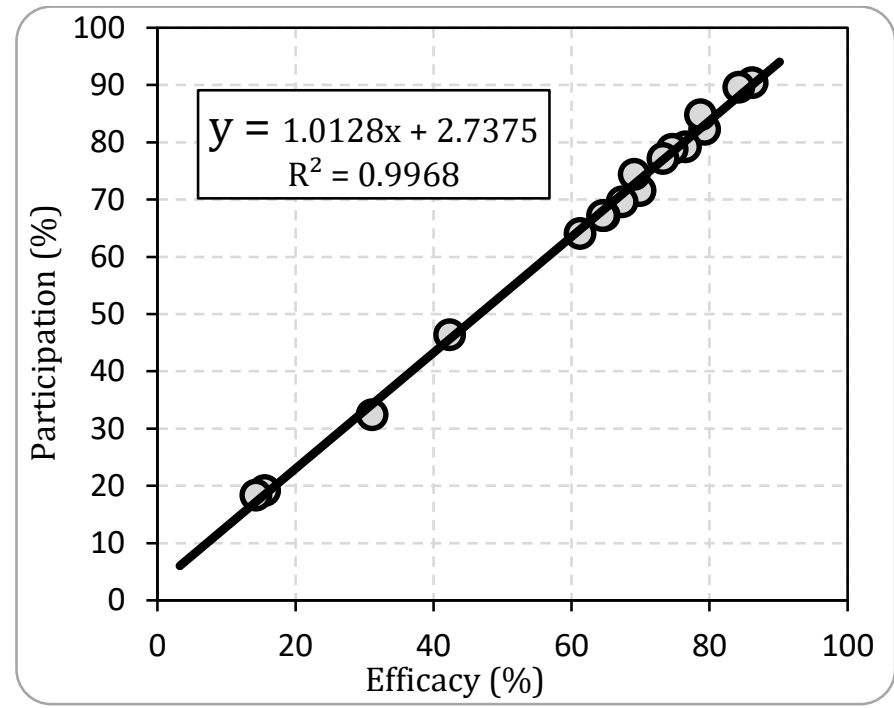

characteristics of service beneficiaries, beneficiary participation in the services, service implementation and implemented service efficacy in the selected rural communities.

The study showed that most of the beneficiaries of AASL-sponsored services were in the most active stage of life, with medium-sized families, decade or so of farming experience and low education. Influenced by the country demography, AASL-services beneficiaries were dominated by male, Muslim and married fractions of the population. The category of attributes under which the beneficiaries fell was described as "productive" - a workforce that was most likely to succeed. Thus, the high success rate of AASL-promoted services was attributed to the fact that most of the beneficiaries fell under the category of attributes classified as productive.

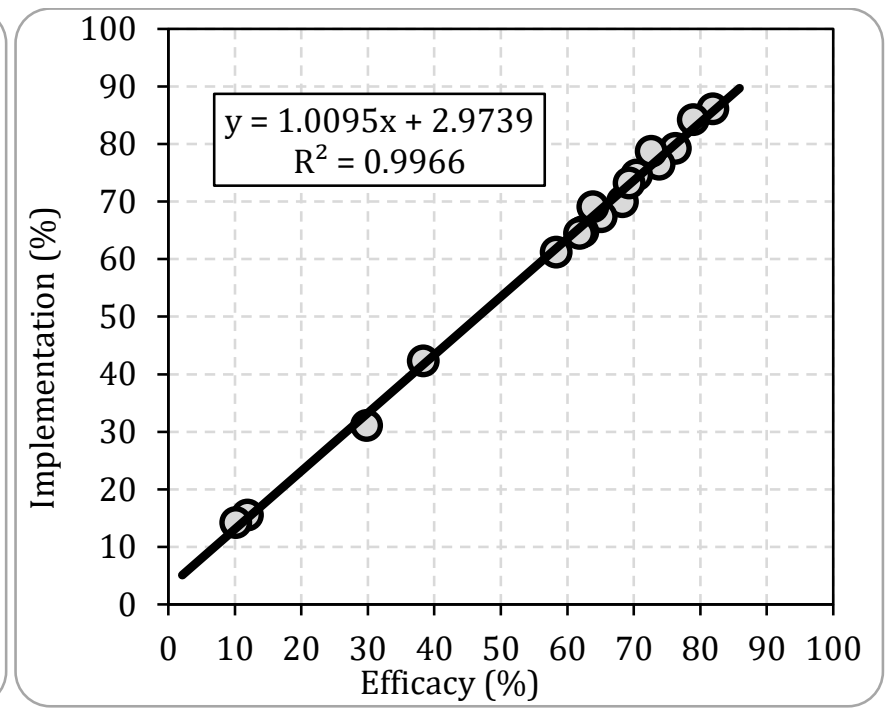

Figure 4. Scatter-plots of service efficiency versus beneficiary participation or agency implementation of AASLprovided services in the Wonde Chiefdom study area in Bo District, Sierra Leone.

The range of services provided by AASL suggested a multi-dimensional development approach to building healthy communities by connecting households with health care, education, farming, technology, knowledge and skill (Olufemi et al., 2015). By engaging in literacy programmes (e.g., teaching, training, construction, etc.), AASL services strengthened the bond between the formal and non-formal environment of rural people. The training opportunities improved farming practices and therefore farm productivity and eventually household income. The provision of small-scale community infrastructures such as schools, markets, toilets, water wells, etc. not only improved hygiene, but also the standard of living of the rural poor in the study area. The participatory approach adopted in AASL-promoted services helped beneficiaries learn to know, do and work together in the communities (Yekini et al., 2012).

Based on the study, most AASL-sponsored services were effective. Farmers seemed interested in programmes that were easy (cheap and simple) to adopt and those that yielded quick returns. Participation and implementation were largely benefit-driven, of which efficacy was a function (Sansui et al., 2010). Although AASL-provided services generally enjoyed high 
participation, implementation and efficacy in the study area, a few others had low successes. The low success of the few cannot be viewed entirely as the lack of interest, but possibly as the memory of bad experience. Governance, corruption and unscrupulous behaviors can turn promising services into suppressive programs in rural communities far from high-end authorities. This was more the reason why the rural poor despised complex programs and services with returns not realizable in the short-term (World Bank, 2009).

\section{CONCLUSION AND RECOMMENDATIONS}

From the findings of the study, it was concluded that AASL-provided services had quick returns (though not exclusive of long-term benefits) and therefore enjoyed high participation, implementation and efficacy. Also, services that spoke to the productive age the population had success rates. However, experience strongly shaped the reaction of rural poor to introduced services, which made even highly promising services hard to succeed.

With this, it was recommended as follows:

- Not only the interests, but also the experiences of beneficiary populations are analyzed in the introduction of community development programs.

- Beneficiary participation requires thoughtful consideration during planning phase of community development programs.

- The key functions of efficacy - accessibility, affordability, suitability, usability and sustainability - should be properly linked with the provision of programs, facilities or services in poor rural communities.

- Efforts must be made to institute programs that are complex and easy to implement in rural communities in sufficiently transparent and accountable ways.

- A similar research is needed not only in other areas where AASL operates, but also where other NGOs operate in the provision of services to rural poor.

\section{REFERENCES}

African Development Bank. (2010). African Economic Outlook Report. Retrieved from. Available at http://www.

Christopolos, I. (2010). Mobilizing the potential of rural and agricultural extension. Rome, Italy: Food and Agriculture Organization (FAO) of the United Nations and the Global Forum for Rural Advisory Services.

Gale, C., Collett, K. \& Freccero, P. (2013), Delivering extension services through effective and inclusive women's groups: The case of SEWA in India. City and Guilds Centre for skills Development, MEAS Case Study \#5. Urbana, USA: Modernizing Extension and Advisory Services (MEAS).

Herbel, D. (2010). Sewa's model of institution building: Empowering small-scale women farmers. Gender, Equity and Rural Employment Division, Economic and social development Department, Food and Agriculture Organization (FAO). Rome, Italy: FAO.

Nxumalo, K. K. S. \& O. I. Oladele. (2013). Factors affecting farmers' participation in agricultural programme in Zululand District, Kwazulu Natal Province, South Africa. Journal of Social Science, 34(1), 8388.

Ministry of Agriculture, Forestry \&Food Security (MAFFS). (2015). Agricultural household survey reports agricultural farm families in Bo District, Southern Sierra Leone

Samah, A. A., \& Aref, F. (2011). The Theoretical and Conceptual Framework and Application of Community Empowerment and Participation in Processes of Community Development in Malaysia, Journal of American Science, 7(2),186195.

Sanusi, M.A., Petu-Ibikunle, A.M \& C. M. Mohelia. (2010). The influence of ICT on the dissemination of agricultural information among urban farmers in the Northern Guinea Savanna zone of Nigeria. African Scientist, 11(2), 135-140.

Statistic Sierra Leone (SSL). (2015). Sierra Leone National Housing and Population Census. https://www.statistics.sl.

World Bank. (2009). Making development climate resilient: A World Bank Strategy for Sub-Saharan Africa (Sustainable Development Department. Report No. 46947-AFR, Africa Region).

Yekini N.A., Rufai M.M., Adetoba, B.T., Akinwole, A.K. \& Ojo, O. (2012). ICT a tool for Poverty Eradication and Economic Growth in Nigeria. Greener Journal of Educational Research, 2(1), 013.

Chiang P. (1981). Non-Governmental Organizations at the United Nations. Identity, Role and Function, (New York: Praeger). [An important early study of the origins and operation of the consultative arrangements in ECOSOC.

Weiss T.G., Gordenker L. (eds.) (1996). NGOs, the UN and Global Governance, (Boulder CO: Lynne Rienner). 
A set of case-studies, set within an analytical framework, across a broad range of types of UN activities.

Cummings, F.H. (1997). Role of participation in the evaluation and implementation of development projects. Knowledge and Policy, 10(1-2), 24-33.

Markus M.L., Mao J. (2004). Participation in Development and Implementation - Updating an
Old, Tired Concept for Today's IS Contexts. Journal of the Association for Information Systems, 5(1112), 514-544.

Ghosh T. (2010). Micro-credit adds to women's double burden in South Asia. http://panoslondon.panosnetwork.org/features/ micro-credit-adds-to-womens-double-burden-insouth-asia/.html. 